\title{
Personality disorder and the Mental Health Act 1983 (amended) ${ }^{\dagger}$
}

\author{
Piyal Sen \& Ashley Irons
}

\begin{abstract}
SUMMARY
The Mental Health Act 1983 now incorporates amendments introduced in 2007. This article explores features of the amended Act that affect the treatment of patients with personality disorder in England and Wales. It discusses issues such as the broad definition of mental disorder, treatability and professional roles, with specific reference to how they might, or might not, affect usual practice concerning patients with personality disorder. It also comments on elements within the Act that could positively affect people with personality disorder, such as community treatment orders, provision to change their 'nearest relative' and statutory advocacy services. The political climate in which the Act has been amended is commented on, as well as how this might potentially compromise some of the positives within the Act
\end{abstract}

\section{DECLARATION OF INTEREST}

None.

The diagnosis and treatment of personality disorder continues to generate much controversy among psychiatrists. There is a strong view within the profession that people with personality disorder should not be considered treatable or, if at all treatable, that treatment should be offered only in specialised centres. Prevalence studies suggest that about $10-13 \%$ of the adult population in England and Wales have a personality disorder (National Institute for Mental Health in England 2003). When considering primary care attendees, estimates rise to around 21\% (Moran 2000).

The purpose of this article is to highlight amendments to the Mental Health Act 1983 for England and Wales of importance to people with personality disorder.

\section{Defining mental disorder}

Under the original (unamended) Act, there were four disorders set out in Section 1.2 (Box 1). If it was proposed that a patient should be detained, the classification needed to fit within at least one of them. The 2007 amendments replaced these four with 'mental disorder', defined as 'any disorder or disability of the mind'. Although the classification 'psychopathic disorder' no longer exists within the Act, we believe that this will not lead to more people with personality disorder being detained.

\section{Effects of the new classification}

It is all very well getting rid of the four separate disorders and replacing them with one, but the fact remains that the burden of proof to justify detention will still be upon the hospital. The responsible clinician has to demonstrate that the mental disorder criteria are met, but importantly that the requisite nature or degree test is satisfied, making detention in hospital necessary for the treatment required. It is not enough under the new regime to simply state that the patient has a mental disorder without defining and evidencing it with greater clinical precision.

\section{Removing 'psychopathic disorder'}

The abolition of the classification 'psychopathic disorder' might well mean that clinicians have to focus on nature and degree, perhaps more so than previously. Before the 2007 amendments, Section 1.2 gave a legal rather than clinical definition, which meant that the disorder had to be persistent and had to be evidenced by 'seriously irresponsible or abnormally aggressive' conduct on the part of the patient. However, at any managers'
Piyal Sen is a consultant forensic psychiatrist and associate medical director for CPD at St Andrew's Healthcare, and a Visiting Research Fellow with the Institute of Psychiatry, King's College London. He runs a personality disorder service in low security and regularly prepares expert reports on patients with personality disorder for mental health review tribunals.

Ashley Irons is Mental Health Partner for Capsticks Solicitors, London. He specialises in representing public and private sector hospitals regarding patients with personality disorder at menta health review tribunals, judicial reviews, inquiries and inquests. Correspondence DrPiyal Sen, St Andrew's Healthcare,

Clare House, Pound Lane, North Benfleet, Basildon SS12 9.JP, UK Email psen@standrew.co.uk.

${ }^{\dagger}$ For a commentary see pp. 336-338.

BOX 1 The four disorders in the original Mental Health Act 1983

- 'Mental disorder' means mental illness, arrested or incomplete development of mind, psychopathic disorder and any other disorder or disability of mind, and 'mentally disordered' shall be construed accordingly.

- 'Severe mental impairment' means a state of arrested or incomplete development of mind which includes severe impairment of intelligence and social functioning and is associated with abnormally aggressive or seriously irresponsible conduct on the part of the person concerned, and 'severely mentally impaired' shall be construed accordingly.

- 'Mental impairment' means a state of arrested or incomplete development of mind (not amounting to severe mental impairment) which includes significant impairment of intelligence and social functioning and is associated with abnormally aggressive or seriously irresponsible conduct on the part of the person concerned, and 'mentally impaired' shall be construed accordingly.

- 'Psychopathic disorder' means a persistent disorder or disability of mind (whether or not including significant impairment of intelligence) which results in abnormally aggressive or seriously irresponsible conduct on the part of the person concerned.

Mental Health Act 1983: Section 1.2 (before the amendments of 2007) 
hearing or mental health review tribunal, the responsible clinician had to demonstrate the impact of the personality disorder upon the patient - and inevitably cited past and recent examples of irresponsible/aggressive conduct, if there were any. If there were none recent, the responsible clinician had to demonstrate that relapse was likely without ongoing treatment in hospital. As the Court of Appeal stated in 2002: 'Psychopathic disorder is defined by reference to a susceptibility to aggression and irresponsible behaviour, in a way that is not the case for other conditions' ( $R \mathrm{v}$. Mental Health Review Tribunal for the East Midlands and North East Region, ex parte P [2002]).

This case is likely to continue to be valid even with the abolition of Section 1.2. It is frequently argued at mental health review tribunals that there have been no presentations suggestive of the existence of a significant disorder and that therefore discharge is the appropriate outcome. However, the opportunity for manifestation in hospital is not the same as in the community.

It could be argued that by abolishing the Section 1.2 requirement for there to be significant irresponsibility/aggression and persistence, individuals with personality disorder are more likely to carry on being detained under the new regime than before. However, we argue that this will not be the case, given the need for the hospital to cite such examples to evidence diagnosis, "nature or degree', risk and hence the need for treatment while detained.

In other words, the scrapping of psychopathic disorder is unlikely to make much difference. However, treatment has never depended on a particular classification of mental disorder ( $R$ v. Ashworth Hospital Authority, ex parte B2005). Perhaps more controversially, broadly the same could be said of the 'treatability test'.

\section{Treatability}

The one seemingly significant change to the detention criteria in the original 1983 Act is to the 'treatability test' (treatment likely to alleviate or prevent a deterioration of the condition). It is replaced in Section 3 by 'appropriate medical treatment' which is 'available for him', i.e. 'medical treatment which is appropriate in his case, taking into account the nature and degree of the disorder and all other circumstances of the case'.

The Department of Health's 2008 Code of Practice for the revised Act seeks to explain this in Section 6.3 (see also Section 35.9):

In the Act, medical treatment for mental disorder means medical treatment which is for the purpose of alleviating, or preventing a worsening of, a mental disorder or one or more of its symptoms or manifestations.

\section{It continues at 6.4 :}

Purpose is not the same as likelihood. Medical treatment may be for the purpose of alleviating, or preventing a worsening of, a mental disorder even though it cannot be shown in advance that any particular effect is likely to be achieved.

That may be so, but clinicians must demonstrate that care or treatment has or will have some effect, however modest.

\section{Abolishing the 'treatability test'}

Since the first draft of the 2007 Mental Health Bill, it has been argued that by abolishing the 'treatability' test, a patient with personality disorder could be detained for treatment even if it had no effect. In other words, a high-risk patient with personality disorder could face longterm incarceration because of risk alone, as the detaining authority would not have to show that the hospital was bringing about an alleviation or prevention of deterioration of the symptoms of the disorder; it would only have to show that appropriate treatment was available.

However, it is significant that this change appears after Section 3.2(c) of the 1983 Act, which states that detention must be 'necessary for the health or safety of the patient or for the protection of other persons that he should receive such treatment and it cannot be provided unless he is detained under this Section'.

We contend that the 'treatability test' remains alive and well in practice, within the amended Act, despite claims that it has been abolished. Our reasons are set out in Box 2.

\section{Professional roles}

Chapter 2 of the amended Act alters professional roles to move away from a purely medical model. The relevance for patients with personality disorder is that psychologists can use the new title 'responsible clinician' and can be in charge of treatment.

\section{The responsible clinician}

The role of a responsible clinician who is a nonpsychiatrist inevitably raises concerns. This is particularly relevant in the case of patients with personality disorder. In many situations, the main therapeutic input is provided by a clinical psychologist and it can be argued that the consultant clinical psychologist is thus best placed to fulfil the role of responsible clinician.

However, this might not be as easy within the current structure of the National Health 
Service (NHS), which is still very much geared to the medical model, despite attempts to develop alternative treatment models through the move to New Ways of Working for Psychiatrists (Royal College of Psychiatrists 2005). The Code of Practice tries to address this by tasking hospital managers with ensuring that the patient has a suitable responsible clinician and that there are cover arrangements in place when the responsible clinician is not available (Department of Health 2008: Section 14.3). This is meant to cover nonworking hours but leads to a potentially bizarre scenario if out-of-hours cover is still provided by psychiatrists, which then raises the question of

\section{BOX 2 Why the 'treatability test' for personality disorder lives on in the amended Mental Health Act}

- The necessity test must mean that a patient cannot be detained unless there is the prospect of benefit. How can detention for the purpose of ineffective treatment ever be necessary?

In $R$ v. Dr Haddock and Others, ex parte JB [2006] before the Court of Appeal the argument concerned both the diagnosis of a patient and whether antipsychotic medication should be given to a patient with personality disorder under Section 58 of the Mental Health Act 1983.

When discussing the threshold that the detaining clinician had to meet in justifying a medication decision, the Court said that it had to be necessary but that necessity was to be defined as 'the likelihood of therapeutic benefit'. It should follow that a patient cannot be detained unless there is 'a likelihood' of benefit from treatment also. It is clear to us that the courts regard the beneficial impact of treatment as a key component to justify why a person should be detained

- To satisfy the appropriateness test at Section 3.4 of the Act, it cannot be appropriate, we argue, for someone to be detained for non-beneficial treatment

- The 'medical treatment' definition in Section 145 of the original Act was that 'it includes nursing, and also includes care, habilitation and rehabilitation under medical supervision' However, this was replaced in 2007 so that it now reads: 'includes nursing, psychological intervention and specialist mental health habilitation, rehabilitation and care ... the purpose of which is to alleviate, or prevent a worsening of, the disorder or one or more of its symptoms or manifestations'.

- The leading authority that has been quoted in every treatability case is Reid v. Secretary of State for Scotland and Anor [1999], which said that the treatability test is 'wide enough to include treatment which alleviates or prevents a deterioration of the symptoms of the mental disorder, not the disorder itself, which it gives rise to'. One can immediately see that the definition of treatability in Reid is largely replicated in the amended Section 145 of the Act - it might even be said that the treatability test has been taken out of Section 3 and put into the revised Section 145

It is therefore our view that the mere availability of treatment is not sufficient. It can be neither appropriate nor necessary if it does not (or is not likely to) have any effect.

\section{South West London and St George's Mental} Health Trust v. W [2002] adopted Eastman's three ways of regarding treatability, which we feel remain valid:

(a) treatment of a patient's core disorder;

(b) seeking to give the patient the skills to enable them to cope with their disorder; or

(c) managing the patient's environment to minimise the disorder's effects.

The Department of Health's 2008 Code of Practice states, at Section 6.17, that simply detaining someone does not constitute medical treatment. However, it never did. One has to demonstrate what it is about therapy, or the therapeutic environment and the efforts of staff, that is having an effect (even if limited to preventing a worsening of the patient's presentation). Thus, even the Code is looking towards something beyond the mere 'availability' of appropriate treatment.

The Code at 6.15 says: 'for some patients with persistent mental disorders, however management of undesirable effects of their disorder may be all that can realistically be hoped for'. At 6.16 it continues: 'there may be patients whose particular circumstances mean that treatment may be appropriate, even though it consists only of nursing and specialist day-to-day care, under the clinical supervision of an approved clinician, in a safe and secure therapeutic environment with a structured regime'. At 35.12 it acknowledges that 'in the majority of cases, the primary model of intervention for personality disorders is rooted in a psycho-social model'.

The bar is not set very high, but we believe that even this last quotation anticipated day-to-day care having a beneficial effect, even if it is limited to preventing deterioration in the 'disorder's effects' that would otherwise take place.
Professor West stated to the Fallon inquiry, which recommended the creation of reviewable sentences for high-risk individuals, that behaviour modification and attitudinal change are essential goals (paragraph 6.8.27). In the same inquiry, Professor Blackburn stated that the notion of 'cure' is not appropriate and total personality change is not a realistic aim. The goal is to produce more adaptive and constructive ways of dealing with situations and relationships that have been problematic in the person's life (paragraph 6.8.14) (Fallon 1999).

In a recent case ( $R v$ v. Secretary of State for Justice, ex parte DK [2010]), a prisoner challenged a decision to transfer him from prison to hospital, where none of the medical reports recommending hospital treatment addressed the issue of treatability. The Court held that the detention was unlawful because detention was only justified if treatment existed that could alleviate or prevent the deterioration of his mental disorders. The significance of this 2010 case is that the Court decided that he should not be detained for treatment in hospital, unless there was evidence of likely benefit from it.

- UK legislation (by virtue of the Human Rights Act 1998) must be read in a way that is consistent with the European Convention on Human Rights. Where there is a conflict, Convention principles will always prevail. The still leading authority on compulsory treatment from the European Court states: 'The Court must nevertheless satisfy itself that the medical necessity has been convincingly shown to exist' (Herczegfalvy v. Austria 1992). If treatment is not medically necessary, it cannot be right for a person with personality disorder to lose their liberty for it to be given. There can also be no necessity to have ineffective treatment. It is thus our conclusion that, for the reasons above, the ingredients of the treatability test remain. However, it is worth noting that this case still dealt with the old Mental Health Act, though the judge noted very clearly in his judgment the meaninglessness of admission to hospital without the prospect of any benefit from treatment. 
BOX 3 Case vignette: out-of-hours decisions

On a Friday night, the duty psychiatrist receives a call from the police saying that they have just arrested a person who was damaging property in the town centre. The person has told them that he has a diagnosis of personality disorder and sees the psychologist attached to the clinical team on a regular basis, and that she is his responsible clinician. However, the responsible clinician is not available to be contacted, because it is out of hours. The duty psychiatrist checks the person's notes and decides on the appropriateness of admission to hospital based on advice from the on-call consultant psychiatrist.

why the psychiatrist would not be the responsible clinician in the first place. This is exemplified in the case vignette in Box 3.

\section{Problems with clinical responsibility}

Another contentious issue is clinical responsibility. The Code of Practice tries to deal with this by stating that the responsible clinician will maintain overarching responsibility for the patient and will be 'kept informed about the treatment' (Department of Health 2008: Section 14.10) . This still does not address the fundamental issue of what happens, for example, when the (non-psychiatrist) responsible clinician's opinion of the patient's needs differs from that of the medical member of the team (Box 4). The non-medical responsible clinician then has all the responsibility with none of the power. This is a bone of contention for professionals managing patients with personality disorder and again, the Code of Practice offers no clarity.

\section{Effects of 'diluting medical authority'}

In an era in which widespread concern has been expressed about the dilution of medical authority (with services being oriented more towards a distributive model of care with emphasis on non-specific psychosocial support, rather than a

BOX 4 Case vignette: who is responsible?

A psychologist is the responsible clinician for a female patient diagnosed as having emotionally unstable personality disorder of the borderline type. The responsible clinician believes that the patient, following the death of her mother, has lapsed into clinical depression and wants an antidepressant to be prescribed. The psychiatrist disagrees because he considers the patient's mood to be a feature of her borderline personality and does not believe that an antidepressant would help. If the patient took her own life, who would carry the responsibility in the inquest? thorough diagnostic assessment and formulation) a patient referred to secondary care may end up never seeing a psychiatrist (Craddock 2008). This so-called dilution of the medical model is of concern to many (Shah 2007). The effect of this on the psychiatric profession could be quite negative (Gee 2007). The broad definition of mental disorder, along with the perceived omission of treatability criteria from the amended Mental Health Act, might lead to a situation in which staff working in an already vulnerable psychiatric profession feel increasing pressure from managers to admit patients, often on political grounds or to manage media headlines - an especially likely scenario for sex offenders (Sen 2007). This is an area of particular concern for psychiatrists managing patients with personality disorder, especially since the exclusion for sexual deviancy has been removed from the amended Act (Box 5). For psychiatrists, the best way to handle this is to argue along the lines described earlier in this article regarding treatability and necessity/appropriateness.

\section{Positives within the amended Act}

Some patients with personality disorder will need long-term treatment. Will the changes enable these patients to continue treatment in the community after being discharged at an earlier stage than before?

\section{Community treatment orders}

Under Section 17A of the amended Act, patients who are currently detained can be made subject to supervised community treatment - in effect, a patient is discharged from hospital subject to recall and conditions. It is separate from the pre-existing Section 17 leave of absence provisions and represents an opportunity for patients to be in the community much earlier than was previously the case. The conditions and safeguards attached to a community treatment order (CTO) provide a way

BOX 5 Case vignette: pressure to admit

The responsible clinician receives a telephone call from the hospital manager. The local Member of Parliament has telephoned the chief executive of the mental health trust about a paedophile who has just been released from prison and has moved into a flat close to a local school. The Member of Parliament is worried about this appearing in the newspapers and wants the paedophile to be assessed and possibly admitted to the psychiatric unit. The chief executive phones the hospital manager and asks that the patient be assessed for admission, as this is possible under the amended Mental Health Act. 
not only to ensure that treatment is available and taken up, but also to manage risk. Risk concerns often delay the pathway into the community for a patient with personality disorder. With such patients on CTOs, it follows that community services will need to make available access to appropriate care and treatment facilities. The potential improvement in services to meet this demand can only be helpful in both reducing the need for these patients to be detained for treatment in the first place, and in shortening the length of any actual detention.

Another benefit of supervised community treatment to detained patients with personality disorder is also apparent. At mental health review tribunals, patients can now argue that both ongoing treatment needs and risk issues can be adequately met by conditions attached to a CTO. The hospital must then explain why detention is necessary for treatment when the same treatment can be given in the community and be a condition of the CTO. Furthermore, risk (it can be argued) is best managed by attendance for ongoing therapy. If treating clinicians in the community feel there is a deterioration, or a likely relapse, the recall provisions can be used.

The potential benefits go further. A detained patient with personality disorder may feel encouraged to cooperate with treatment to make progress, thus enabling supervised community treatment to become a real possibility. Leaving a hospital on a CTO would be a nearer prospect than a later discharge. The criteria for a CTO (Box 6) appear in Section 17A.5 of the amended Act. The conditions that can be attached to a CTO, for example, can relate to residence or attending hospital at specified intervals and can require the patient to abstain from particular conduct. Breach of conditions might lead to recall if there is a significant risk of harm to the patient or others were the patient to remain in the community (Section 17E).

Community treatment orders cannot be imposed on anyone who is already in the community. They can only apply to those currently detained, as a condition of residing in the community. Conditions of CTOs could include attendance for therapy, for example. Community treatment orders may be useful for some patients with substance misuse problems to enforce their abstinence from using illicit substances in the community, or for a sex offender to enforce adherence to treatment.

\section{Compulsory treatment}

It is worth considering the practical effect of compulsory treatment for those on supervised community treatment and its very different
BOX 6 Criteria for a community treatment order in the amended Mental Health Act

a The patient is suffering from mental disorder of a nature or degree which makes it appropriate for him to receive medical treatment.

b It is necessary for his health or safety or for the protection of other persons that he should receive such treatment.

c Subject to his being liable to be recalled as mentioned in paragraph $d$ below, such treatment can be provided without his continuing to be detained in a hospital.

d It is necessary that the responsible clinician should be able to exercise the power ... to recall the patient to hospital.

e Appropriate medical treatment is available for him

(Mental Health Act 1983 (Amended), Section 17A.5)

effects, in our view, on patients with mental illness requiring medication and patients with personality disorder requiring therapy.

Patients who are mentally ill often remain detained because of lack of insight, as they will not voluntarily receive the medication prescribed. Indeed, the judgment in $R$ v. London South West Region Mental Health Review Tribunal, ex parte Moyle [1999], when considering the 'nature' of the individual's illness, illustrates this:

The correct analysis, in my judgement, is that the nature of the illness of a patient such as the Applicant, is that it is an illness that will relapse in the absence of medication. The question that then has to be asked is whether the nature of that illness is such as to make it appropriate for him to be liable to be detained in hospital for medical treatment. Whether it is appropriate or not will depend upon an assessment of the probability that he will relapse in the near future if he were free in the community.

In other words, a CTO will ensure that a patient lacking insight will have their depot medication, for example, but what of a patient with personality disorder? It is quite foreseeable that the facility of treatment orders will enable more mentally ill patients to leave hospital, but will those beds be taken up by patients with personality disorder? After all, one can hardly expect therapy to be effective if it required coercion to get a patient with personality disorder to attend a psychologist for it. Will it mean that such patients who are recalled are more likely to be detained beyond 72 hours, after which the CTO lapses and detention resumes?

\section{Community treatment orders $v$. standard care}

The largest systematic review of CTOs, commissioned by the Department of Health, found some evidence that the orders do not have any effect on key outcomes such as hospital readmissions, length of hospital stay, improved medication adherence or patients' quality of life (Churchill 2007). It has 
MCQ answers

$\begin{array}{lllll}1 \text { e } & 2 \mathrm{c} & 3 \mathrm{c} & 4 \mathrm{~b} & 5 \mathrm{a}\end{array}$ thus been queried whether they can be an effective alternative to standard care (Kisely 2005) in cases of severe mental illness. There continues to be a debate within the psychiatric profession on this issue, with its proponents arguing that if used judiciously, CTOs would offer significant benefits to users and carers in the form of better psychiatric care (Lawton-Smith 2008).

No separate data are provided for patients with personality disorder. It could be argued for these patients that, when unescorted leave of absence has been extended and worked without a deterioration of the disorder and/or increase in risk indicators, the CTO may become a real incentive with which to encourage patients to engage in therapy and thereby make progress.

Using the CTO as a positive incentive (rather like a conditional discharge order that is available to a mental health review tribunal for restricted patients) could be a way to maintain them in the community, instead of detaining them for prolonged periods in hospital. However, as with most things, what matters if this is to work is adequate resourcing of community services and staff who possess the requisite skills, in this case the management of personality disorder. Otherwise, the beds made available by mentally ill patients being managed in the community could end up being occupied by patients with personality disorder about whom there is public and staff anxiety. Overall, the provision of a CTO could have a beneficial impact on patients with personality disorder if used judiciously by staff with adequate skills.

\section{The 'nearest relative'}

Another positive development arising from the 2007 amendments is the change in the provision of a 'nearest relative'. A large proportion of patients with personality disorder have difficult relationships with family members and are unable to use their 'nearest relative' to their advantage. However, under Section 29.3(e) of the amended Mental Health Act they may now be able to replace someone who is 'not a suitable person' with someone of their choice, by making an application to the county court.

\section{Provision of information}

The last area concerns the provision of information and advocacy. When a patient is detained under the Mental Health Act or becomes subject to supervised community treatment, the hospital managers have a duty to ensure that appropriate important information about the workings of the Act is given straight away. The information to be given is quite detailed and will empower patients, their advocates and nearest relatives to challenge decisions being made (see Sections 2.1-2.46 in the Code of Practice).

The duty to give information includes information about independent mental health advocates (Section 130D of the Act). It is quite clear from the Code of Practice (chapter 20) that independent mental health advocates are intended to offer a more proactive service than may have been the case before the 2007 amendments to the Act. They are entitled to see patient records and assist with representation at tribunal and managers' hearings or care programme approach meetings. There is now a statutory requirement that this service be in place for all patients and it may become a particularly useful source of advice and support for vulnerable patients with personality disorder.

\section{The future}

It is far too early to say whether the amended Mental Health Act will change the way psychiatry is practised in this country. Experience in the USA suggests that it will not (Appelbaum 1984). The amended Act has been criticised as 'stigmatising, illiberal and yet curiously timid ... a little like a dying wasp which still has a sting in it' (Murphy 2006). It has been felt to be 'too sensitive to individual high profile tragedies' and as being 'so broad that it potentially includes most violent offenders' (Crichton 2007). It has failed to achieve the principle of basing compulsion primarily on capacity and not on risk to others, which thus continues to drive a wedge between mental health and general medical law. This can create ethical concerns for psychiatrists (Lepping 2008).

The amended Mental Health Act has arrived in a climate in which there has been an overwhelming shift of power over clinical service development from the professions to the government in the previous two decades (Burns 2004). It also comes at a time when there is a huge debate within the psychiatric profession about psychiatry's role in British society (Bhugra 2008). Furthermore, there has been a dramatic fall in the number of NHS psychiatric beds along with an increase in involuntary admissions over the past decade in England (Keown 2008).

Psychiatric professionals have been feeling the pressure, since they also carry the responsibility when things go wrong for people with mental illnesses in the community, especially for patients previously detained. The pressures will only intensify in the current economic climate with severe financial pressures on the NHS. The amended Act could potentially worsen the situation, particularly if more people with personality disorder are 
admitted to hospital involuntarily. One sincerely hopes that a Mental Health Act amended at a time of such mutual mistrust between the profession and the government is used in a way that 'is ethical, workable and effective if it is to win over the hearts and minds of many of those who have to operate it, or will be subject to its provisions', to quote Tony Zigmond (in the pages of this journal), the principal advocate for the Royal College of Psychiatrists while the Bill was passed through Parliament (Zigmond 2008). It is important, however, not to lose sight of some positive opportunities within the Act to offer a better service to patients with personality disorder, a group all too often neglected by psychiatric services.

\section{References}

Appelbaum PS (1984) Almost a Revolution: Mental Health Law on the Limits of Change. Oxford University Press.

Bhugra D (2008) Reviewing psychiatry's contract with society. Psychiatric Bulletin 32: 281-3.

Burns T (2004) Psychiatry in the future. Changes in UK mental health care over the past 15 years. Psychiatric Bulletin 28: 275-6.

Churchill R, Owen G, Singh S, et al (2007) International Experience of Using Community Treatment Orders. Department of Health.

Craddock N, Antebi D, Attenburrow M-J, et al (2008) Wake-up call for British psychiatry. British Journal of Psychiatry 193: 6-9.

Crichton J, Darjee R (2007) New mental health legislation. BMJ 334: 596-7.

Department of Health (2008) Code of Practice: Mental Health Act 1983. Published Pursuant to Section 118 of the Act. TSO (The Stationery Office).

Fallon P, Bluglass R, Edwards B, et al (1999) Report of the Committee of Inquiry into the Personality Disorder Unit, Ashworth Special Hospital (2 volumes and Executive Summary) (Cm: 4194 I \& II). TSO (The Stationery Office).

Gee M (2007) New Ways of Working threaten the future of the psychiatric profession. Psychiatric Bulletin 31: 315

Keown P, Mercer G, Scott J (2008) Retrospective analysis of hospital episode statistics, involuntary admissions under the Mental Health
Act 1983, and number of psychiatric beds in England 1996-2006. BMJ 337: $976-8$.

Kisely S, Campbell LA, Preston N (2005) Compulsory community and involuntary outpatient treatment for people with severe mental disorders. Cochrane Database of Systematic Reviews, issue 3, CD004408.

Lawton-Smith S, Dawson J, Burns T (2008) Community treatment orders are not a good thing. British Journal of Psychiatry 193: 96-100.

Lepping $P(2008)$ Is psychiatry torn in different ethical directions? Psychiatric Bulletin 32: 325-6.

Moran P, Jenkins R, Tylee, A, et al (2000) The prevalence of personality disorder among UK primary care attenders. Acta Psychiatrica Scandinavica 102: $52-7$.

Murphy E (2006) Mental Health Bill. Second reading. Hansard, HL, vol 687, part 8, cols 718-9 (28 Nov)

National Institute for Mental Health in England (2003) Personality Disorder: No Longer a Diagnosis of Exclusion. Policy Implementation Guidance for the Development of Services for People with Personality Disorder. Department of Health.

Royal College of Psychiatrists, National Institute for Mental Health in England (2005) New Ways of Working for Psychiatrists. Enhancing Effective, Person-Centred Services through New Ways of Working in Multidisciplinary and Multi-Agency Contexts. Final Report 'But Not the End of the Story.' Department of Health.

Sen P, Adeleke D (2007) Sex sells, but does it help? A survey of media coverage in a medium secure unit treating sex offenders. Mental Health Review Journal 12: 15-21.

Shah P, Mountain D (2007) The medical model is dead. Long live the medical model. British Journal of Psychiatry 191: 375-7.

Zigmond T (2008) Changing mental health legislation in the UK. Advances in Psychiatric Treatment 14: 81-3.

Herczegfalvy v. Austria (1992) 15 EHRR 437.

$R$ v. Ashworth Hospital Authority, ex parte B [2005] UK HL 20.

$R$ v. Dr Haddock and Others, ex parte JB [2006] ELOCA civ 961.

$R$ v. Mental Health Review Tribunal for the East Midlands and North East Region, ex parte $P$ [2002] ECWA Civ 697.

$R$ v. London South West Region Mental Health Review Tribunal, ex parte Moyle [1999]

$R$ v. Secretary of State for Justice, ex parte DK [2010] EWHC 82

Reid v. Secretary of State for Scotland and Anor [1999] 2 WLR 28

South West London and St George's Mental Health Trust v. W [2002] EWHC 1770 Admin.

\section{MCQs}

Select the single best option for each question stem

1 The 2007 amendments to the Mental Health Act abolished the following classifications:

a mental illness

b psychopathic disorder

c mental impairment

d severe mental impairment

e all of the above.

2 Under the amended Act, a patient can be detained if the following conditions for treatment are met:

a treatment is legal

b treatment is offered by a psychiatrist c treatment is available and appropriate

d treatment has an effect on risk

e treatment will cure the mental disorder.

3 The conditions for a community treatment order for personality disorder can include:

a working in a certain occupation

b regular contact with family

c attending hospital at specified intervals

d not driving a car

e not obtaining a passport.

4 The provision in the amended Act that helps to uphold the human rights of a patient with personality disorder is:

a ease of discharge

b provision of statutory advocacy service c right to refuse treatment if the patient possesses capacity

d regular contact with 'nearest relative'

e more frequent tribunal hearings.

5 The following is potentially not a positive feature of the amended Act in the treatment of personality disorder:

a removal of treatability clause

b community treatment orders

c right to change 'nearest relative'

d provision of statutory advocacy service

e none of the above. 